FP3 (continued)

six months after training. Surveys revealed participants increased their culinary knowledge and skills, comfort level in preparing menu items from scratch, and amount of scratch cooking done at their school. Additionally, participants increased the variety of menu items offered by incorporating the recipes used in the trainings into the school menus.

Conclusions and Implications: In-person and webbased trainings are effective ways to teach culinary skills, introduce new foods, and increase the amount of scratch cooking done at schools. Scratch cooking can be a way to expand the variety of healthy school lunch offerings. This may assist schools in meeting the USDA Target 2 sodium guidelines by reducing the number of high sodium processed foods served in school meals.

Funding: USDA Team Nutrition Training Grant, CNTN14-WI, CNTN-12-WI

\section{FP4 Michigan School Nutrition Programs Team Nutrition Smarter Lunchroom Initiative}

Nicholas Drzal, MPH, RD, DrzalN@michigan.gov, Michigan Department of Education, PO Box 30008, Lansing, MI 48909; Mark A. Lelle, Michigan Department of Education; Katherine Alaimo, PhD, Michigan State University; Becky Henne; Liz Dorman; Coleen Joseph; Meghan Donovan

Objective: To increase the number of Michigan schools implementing Smarter Lunchroom strategies.

Description: A Michigan Smarter Lunchroom (SL) partnership with Michigan State University Extension (MSUE) and other state level partners was formed to pilot a coaching model and increase the number of schools implementing SLs. The initiative included: funding 50 schools $\$ 350$ each to implement SL strategies; training food service professionals in SL techniques; creating and distributing YouTube videos; and promoting successes through social networking websites. Evaluation: A total of 46 schools completed all sub-grant requirements. All food service professionals and MSUE staff $(100 \%)$ responding to the end of year survey reported feeling that they increased either their own or their staffs' knowledge of smarter lunchrooms. Twenty-one of the 46 preand post-score cards were analyzed and showed that all ten subcategories increased in average scores, with the greatest increases in scores occurring in the Focus on Fruit, Moving More White Milk, and Creating School Synergies subcategories. Thirty-two success stories were compiled in a compendium for ease of sharing. Team Nutrition (TN) social media efforts resulted in the best practice videos being viewed more than 1,150 times. Total views of all Michigan Team Nutrition videos to date exceed 48,000 views. The estimated number of school children reached through the effort was 19,248 students, with an average percentage eligibility for free or reduced lunch among the schools being 50\%.

Conclusions and Implications: Increasing statewide smarter lunchroom participation requires a long term, multi-pronged, collaborative effort. Other states should consider modifying MTN's intervention materials to promote participation in SL.

Funding: USDA Team Nutrition Training Grant, TN2014
FP5 Integrated Culinary Skills and School Food Environment Intervention Training and Plate Waste in School Lunchrooms - A Review of Preliminary Results from South Carolina's Team Nutrition Efforts

Kathryn I. Hoy, LDN, RD, MFN, khoy@email.sc.edu, University of South Carolina, Arnold School of Public Health, Discovery 1, 915 Greene Street, Columbia, SC 29208; Krystal Waldrop, BS, South Carolina Department of Education; Juanita Bowens-Seabrook, PhD

Objective: South Carolina's Team Nutrition efforts aim to increase the knowledge, skills, and capacity of school foodservice staff through culinary and Smarter Lunchrooms training and technical assistance.

Description: Throughout the 2016 school year approximately 500 school foodservice staff from across 27 strikeforce counties were trained in behavioral economics techniques and culinary skills. Technical assistance and tool-kits were provided to participant schools with the goal of enhancing the school food environment while increasing the taking and consumption of healthful foods by students.

Evaluation: A trained graduate student completed plate waste and the Smarter Lunchrooms Self-Assessment scorecard at 36 randomly selected school sites throughout the strikeforce area to establish a baseline measure of waste and serving sizes. To date, plate waste measurements and scorecards have been repeated at 15 of the previously measured sites. Descriptive statistics and paired t-tests were completed to determine if change in plate waste was significant.

Conclusions and Implications: A total of $n=7593$ trays were observed from 36 school sites with approximately 210 lunch trays observed per site visit. All food items were divided into the following categories for analysis: entree, starchy side, $1 \%$ white milk, skim flavored milk, salad, hot vegetables and canned fruit. Preliminary analysis indicates an $\sim 69 \%$ decrease in total waste per serving between the pre- and post- plate waste measurement. Serving sizes also decreased by an average of $7 \%$ for entrees and increased by an average of $10.93 \%$ for fresh fruit, hot vegetables, and canned fruit. Further analysis is needed to determine the nature of these decreases and the true impact of these training programs on overall child dietary patterns.

Funding: USDA Team Nutrition Training Grant, \# CNTN15- SC

\section{FP6 California's Smarter Lunchrooms + Nutrition Education = Increased Youth Connection with School Cafeterias}

Heather Reed, MA, RD, hreed@cde.ca, California Department of Education, 1430 North Street, Suite 4305, Sacramento, CA 95814; Deborah Tamannaie, MS, RD, California Department of Education; Crystal Young, BS; Shannan Young, RD, SNS, Dairy Council of Califoria; MaryAnn Mills, BS, UC CalFresh Nutrition Education Program; Leslie Pring, BS, SNS, Dairy Council of California 
FP6 (continued)

Objective: To enhance Smarter Lunchrooms Movement (SLM) implementation in California schools by aligning with Nutrition Education (NE).

Description: The California Department of Education (CDE) administered Team Nutrition (TN) SLM mini-grants in 48 schools. Schools completed action plans for 3 SLM and 2 NE interventions during school year 2016-17. CDE conducted 4 workshops, 5 webinars, and onsite visits. Certified Technical Advising Professionals (TAPs) from the Dairy Council of CA (DCC) and UC CalFresh Nutrition Education Program (UC) provided support for NE and SLM. SLM applies behavioral economics to nudge students toward healthy choices and is proven successful in school cafeterias. Combining NE with SLM increases healthy food consumption.

Evaluation: Pre/post evaluations include staff surveys; SLM Scorecards; plate waste; food production/sales records and/or student surveys; meal participation; and NE. Mid-Project Reports documented average NE Interventions/school of 3.42; reaching 316 students/school (total-15,171). NE activities included taste testings (79\%), student art promoting healthy choices (15\%), and assemblies (39\%). Delivery was at the cafeteria (69\%); school events (35\%); classroom (35\%) and after school (10\%). NE resources were from DCC $(73 \%)$; TN (60\%), Harvest of the Month (56\%); and UC (19\%).

Conclusions and Implications: Effective SLM-aligned NE strategies are youth-centered and easier to initiate outside the classroom. In many schools, students tasted menu items, participated in naming contests, helped with promotional murals, attended interactive assemblies, and some served as nutrition ambassadors or on advisory councils. Food Service reported feeling more connected to the school and students, and saw improvements in meal participation and waste reduction. Final evaluation available June 2017, including case studies and toolkits.

Funding: USDA Team Nutrition Training Grant, \# CNTN-15-CA California Department of Education; Smarter Lunchrooms Movement of California Collaborative

\section{FP7 Nebraska Team Nutrition (NE TN) Sustains the School Enrichment Kit (SEK) Program Through Elementary Health Liaison Teacher Training \\ Zainab Rida,PhD,LDN, RD, zainab.rida@nebraska.gov,} Nebraska Department of Education, 301 Centennial Mall South, Lincoln, NE 68509; Kristen Houska, MS, University of Nebraska-Extension; Jean Ann Fischer, MS, LDN, RD; Jessica Meuleners, MS, LDN, RD; Matt Avey, PhD, Lincoln Public School District

Objective: Identify a successful strategy of increasing the nutrition and physical activity training that targets K-5 elementary teachers. Describe the key com- ponents of the SEK that align with the 2015 Dietary Guidelines for Americans (DGA) and Local School Wellness Policy.

Description: The purpose of this project was to evaluate the impact of the Team Nutrition (TN) Training Workshops that targeted K-5 teachers, students and parents in schools. A trainthe-trainer model was followed and targeted a K-5 health liaison teacher team. The model included a NE TN developed training workshop and three-20 minute videos to distribute to the health liaison teachers $(n=36)$. The liaisons then were able to send the videos for viewing to their colleagues across all grades at their school as training for their health unit. NE TN utilized the School Enrichment Kit (SEK) program to help schools meet School Wellness Policy elements through the SEK core concepts that align with the 2015 DGA. Six $(n=6)$ schools $(n=4$ intervention and $n=2$ control) were randomly selected to participate in this study.

Evaluation: Formative and summative evaluations were conducted to assess the impact of the workshop on teachers in their teaching of nutrition for K-5 students. The impact of the teaching of nutrition directly on K-5 students and indirectly on parents were assessed in terms of knowledge and/or behavioral changes.

Conclusions and Implications: Offering nutrition and physical activity education workshops will provide teachers with competencies that enable them to effectively mentor and facilitate the knowledge, application, and skills necessary to teach nutrition and physical activity to elementary students. Therefore, this practice may lead to increased classroom instruction time on nutrition and physical activity.

Funding: USDA Team Nutrition Training Grant, \# CNTN15-NE

\section{FP8 South Dakota Team Nutrition: Farmer Grow MyPlate and Power Chef Challenge}

Suzanne Stluka, MS,LDN, RD, Suzanne.Stluka@sdstate. edu, South Dakota State University Extension, SWG 435, Box 2275A, Brookings, SD 57007; Megan Jacobson, MS, $L D N, R D$, South Dakota State University Extension; Karlys Wells, MS; Jill Cotton, South Dakota Department of Education; Sandra Kangas

Objective: Increase nutrition education by motivating students to use MyPlate to eat healthfully as well as to teach how MyPlate foods are produced. Provide culinary and nutrition education training to school nutrition professionals, elementary and middle school students with the Power Chef Challenge.

Description: Farmers Grow MyPlate uses each of the USDA MyPlate food groups as the focus to provide hands-on lessons on nutrition, physical activity, food preparation, food safety, and food production. Lesson implementation, food preparation activities and especially field trips to farms and markets are being supported with sub-grants for use in summer day camps, school classrooms, after-school programs, and summer child care settings. Power Chef Challenge is a nutrition education program teaching basic food preparation skills with the intent of having youth participants share and prepare 